\title{
Confronting Uncertainties of Simulated Air Pollution Concentrations during Persistent Cold Air Pool Events in the Salt Lake Valley, Utah
}

\section{Supporting Information}

Xia Sun ${ }^{1,2 *}$, Cesunica E. Ivey ${ }^{3}$, Kirk R. Baker ${ }^{4}$, Athanasios Nenes ${ }^{5,6}$, Neil P. Lareau ${ }^{7}$, Heather A. Holmes ${ }^{8}$

1. Cooperative Institute for Research in Environmental Sciences, University of Colorado, Boulder, Colorado 80309, United States

2. NOAA Global Systems Laboratory, Boulder, Colorado 80305, United States

3. Civil and Environmental Engineering University of California, Berkeley, California 94720, United States

4. U.S. Environmental Protection Agency, Research Triangle Park, North Carolina 27703, United States

5. Institute for Chemical Engineering Sciences, Foundation for Research and Technology Hellas, Patras, GR-26504, Greece

6. School of Architecture, Civil \& Environmental Engineering, Ecole Polytechnique Fédérale de Lausanne, CH-1015, Lausanne, Switzerland

7. Atmospheric Sciences Program, Department of Physics, University of Nevada, Reno, Nevada 89557, United States

8. Department of Chemical Engineering, University of Utah, Salt Lake City, Utah 84112, United States

* Corresponding author: Xia Sun (xia.sun@noaa.gov)

Number of tables: 2

Number of figures: 11 


\section{S1 WRF Model Setup}

The Asymmetric Convective Model version 2 (ACM2) PBL scheme uses a combination of local and non-local turbulence closure schemes and is reported to generate more mixing in the boundary layer compared with both local schemes and non-local schemes [1]. The Yonsei University (YSU) PBL scheme uses a non-local closure scheme. The Mellor-Yamada-Janjic (MYJ) and MellorYamada-Nakanishi-Niino (MYNN) schemes both use local closure schemes that use turbulent kinetic energy to determine the eddy diffusivity coefficients [2]. The MYNN scheme uses large eddy simulation results to estimate stability and mixing length rather than values based on observations as in the MYJ scheme [3]. Other uniform physical parameterizations across the WRF simulations included Thompson cloud microphysics scheme [4], RRTM scheme for longwave radiation [5], Dudhia scheme for shortwave radiation [6], and Kain-Fritsch cumulus scheme [7].

All four WRF simulations were configured using two two-way nested domains. The outer domain covered the Contiguous United States (CONUS) with $12 \mathrm{~km}$ horizontal resolution. The inner domain was centered on the Salt Lake Valley and encompasses much of Utah, southwest of Idaho, western Wyoming, and northwestern Colorado with a $4 \mathrm{~km}$ horizontal resolution. The vertical grids included 41 layers with 20 levels below $1 \mathrm{~km}$. The initial and boundary meteorological conditions were provided by the National Centers for Environmental Prediction's (NCEP) North American Mesoscale (NAM) model, including the NAM reanalysis dataset $(0000$, 0600, 1200, and 1800 UTC) and the NAM forecasting dataset (0300, 0900, 1500, and 2100 UTC). Four-dimensional data assimilation (FDDA) was implemented in the WRF simulations similar to Otte [8]. For better model performance, we restarted the model every six days with one day as the model spin up time to cover the whole January of 2011. The ModACM2 case that used the Pleim- 
Xiu LSM ran for an extra 10 days for model spin up to initialize its own soil nudging as recommended by Gilliam and Pleim [9].

\section{S2 Vertical Profiles of Temperature and Aerosol Backscatter}

Qualitative comparisons of simulated and observed potential temperature, as well as simulated $\mathrm{PM}_{2.5}$ concentrations and lidar profiles of aerosol backscatter, are presented in Figure S2 for PCAP3, where large deficiencies existed for H22. The lidar backscatter profiles are taken as approximations of the $\mathrm{PM}_{2.5}$ mass [10] and can also provide information on cloud formation. For example, stratiform boundary layer clouds were observed overnight on 28 Jan to 30 Jan. The observations show that strong stratifications occurred during the clear night on 27 Jan and 28 Jan. Weaker near-surface stratification with more mixing due to the limited surface radiative cooling (figure not shown) occurred on nights with boundary layer clouds (28 Jan to 30 Jan). The atmospheric stratifications were more intense above the cloud to the ridge height (2200 m MSL) because of the cloud top radiative cooling on cloudy nights compared with clear nights. This yields an increased $\mathrm{H} 22$ (Figure 1) and is accompanied by enhanced surface $\mathrm{PM}_{2.5}$ concentrations (Figure 2).

The model generated less stable atmospheric stratification according to the potential temperature contour lines, compared with the Radio Acoustic Sounding System (RASS) observations at the ISS site during PCAP3 (0300 MST 27 Jan to 1800 MST 30 Jan). The ModYSU showed more mixing compared with other models. This leads to an underestimated H22 at the same time, which partly accounts for the underestimated $\mathrm{PM}_{2.5}$ concentrations. The strongest atmospheric stratification below ridge height occurred on the night of 28 Jan to 29 Jan in simulations that was one day before the observations (on the night of 29 Jan to 30 Jan). This leads to a faster depletion of surface $\mathrm{PM}_{2.5}$ levels in the models compared to observations. 


\section{$\mathrm{S3} \mathrm{SO}_{2}$ Simulation Analysis}

Consistently high $\mathrm{SO}_{2}$ concentrations were simulated by the CMAQ runs (Figure S5). The maximum $\mathrm{SO}_{2}$ level from simulations reached up to $13.2 \mathrm{ppb}$, which was around three times higher than the observations (4.7 ppb). The low observed $\mathrm{SO}_{2}$ levels might be related to improvements in the smelting processes and equipment from local mining companies (personal communication with Bradley R. Adams, Brigham Young University). Impacts associated with these kinds of local activities on $\mathrm{SO}_{2}$ levels are not included in the emission inventory estimates or the emissions processing models [11]. There were no distinct diel patterns in the $\mathrm{SO}_{2}$ observations. Overestimations of simulated $\mathrm{SO}_{2}$ mainly occurred during daytime (Figure S6). Interestingly, the overestimation of $\mathrm{SO}_{2}$ (Figure S5) did not lead to an overestimation of sulfate. Underestimation of sulfate in the cold season has also been reported by Tesche, Morris, Tonnesen, McNally, Boylan and Brewer [12], which might be attributed to uncertainties in the chemical processes converting $\mathrm{SO}_{2}$ to sulfate in the CMAQ model. 
Table S1 Details of the PBL schemes, surface layer schemes, and LSM options used in the four WRF model experiments

\begin{tabular}{cccc}
\hline Experiment & PBL scheme & Surface layer scheme & LSM \\
\hline \multirow{2}{*}{ ModACM2 } & ACM2 [13] & Pleim-Xiu & Pleim-Xiu \\
& YSU & {$[14]$} & {$[15]$} \\
ModYSU & {$[16]$} & Revised MM5 & Noah [18] \\
& MYJ & {$[17]$} & \\
ModMYJ & {$[19]$} & Eta similarity & Noah \\
ModMYNN & MYNN & {$[19]$} & Noah \\
\hline
\end{tabular}

Table S2 Statistical comparisons of hourly simulated and observed $\mathrm{NO}_{\mathrm{x}}, \mathrm{O}_{3}, \mathrm{SO}_{2}$, and $\mathrm{PM}_{2.5}$ at the HW site during PCAPs/non-PCAPs. The $\mathrm{r}$ values are significant at $95 \%$ confidence level.

The model experiments with the least NME were denoted with *.

\begin{tabular}{|c|c|c|c|c|c|c|}
\hline & $\mathrm{MB}$ & $\mathrm{ME}$ & NMB & NME & $\mathrm{r}$ & IOA \\
\hline \multicolumn{7}{|l|}{ NO $_{\mathbf{x}}(\mathrm{ppb})$} \\
\hline ModACM2* & $4.65 / 8.66$ & $58.46 / 49.64$ & $5.19 / 13.04$ & $65.22 / 74.72$ & $0.15 /-$ & $0.48 / 0.39$ \\
\hline ModYSU & $20.56 / 17.53$ & $64.97 / 62.84$ & $22.94 / 26.38$ & $72.47 / 94.59$ & $0.20 /-$ & $0.49 / 0.28$ \\
\hline ModMYJ & $18.34 / 25.05$ & $69.68 / 64.46$ & $20.46 / 37.71$ & $77.74 / 97.03$ & $-1-$ & $0.40 / 0.28$ \\
\hline ModMYNN & $17.42 / 19.95$ & $65.97 / 61.16$ & $19.44 / 30.03$ & $73.59 / 92.07$ & $0.15 /-$ & $0.46 / 0.29$ \\
\hline \multicolumn{7}{|l|}{$\overline{\mathbf{O}_{3}(\mathrm{ppb})}$} \\
\hline ModACM2 & $0.41 /-2.04$ & $5.94 / 6.89$ & $6.58 /-20.48$ & $95.70 / 69.22$ & $0.33 / 0.54$ & $0.58 / 0.71$ \\
\hline ModYSU & $0.68 /-0.12$ & $6.90 / 8.75$ & $11.00 /-1.22$ & $111.11 / 87.95$ & $0.13 / 0.29$ & $0.41 / 0.57$ \\
\hline ModMYJ* & $-0.26 /-2.27$ & $5.90 / 7.76$ & $-4.21 /-22.78$ & $94.96 / 78.00$ & $0.23 / 0.40$ & $0.51 / 0.61$ \\
\hline ModMYNN & $0.48 /-1.30$ & $6.56 / 7.67$ & $7.74 /-13.11$ & $105.70 / 77.05$ & $0.21 / 0.42$ & $0.48 / 0.65$ \\
\hline \multicolumn{7}{|l|}{$\mathrm{SO}_{2}(\mathrm{ppb})$} \\
\hline ModACM2 & $0.58 / 0.44$ & $1.32 / 0.87$ & $37.06 / 36.68$ & $84.66 / 93.44$ & $-/ 0.15$ & $0.19 / 0.24$ \\
\hline ModYSU & $1.15 / 0.73$ & $1.72 / 1.19$ & 73.77 / 61.33 & $109.82 / 99.67$ & $-/ 0.23$ & $0.17 / 0.20$ \\
\hline ModMYJ* & $0.56 / 0.49$ & $1.20 / 0.86$ & $36.00 / 40.80$ & $76.82 / 72.30$ & $-/ 0.20$ & $0.23 / 0.23$ \\
\hline ModMYNN & $0.85 / 0.51$ & $1.49 / 0.92$ & $54.38 / 43.22$ & $95.08 / 77.49$ & $0.13 / 0.22$ & $0.20 / 0.24$ \\
\hline \multicolumn{7}{|l|}{$\mathbf{P M}_{2.5}\left(\mu \mathrm{g} \cdot \mathrm{m}^{-3}\right)$} \\
\hline ModACM2 & $-17.37 / 0.23$ & $20.86 / 10.69$ & $-41.45 / 1.45$ & $49.79 / 67.32$ & $0.34 / 0.15$ & $0.50 / 0.45$ \\
\hline ModYSU* & $-13.30 / 2.25$ & $17.89 / 11.10$ & $-31.76 / 14.14$ & $42.71 / 69.88$ & $0.49 / 0.33$ & $0.61 / 0.59$ \\
\hline ModMYJ & $-15.23 / 2.70$ & $19.00 / 11.59$ & $-36.36 / 17.02$ & $45.35 / 72.93$ & $0.45 / 0.23$ & $0.57 / 0.52$ \\
\hline ModMYNN & $-14.03 / 2.54$ & $18.34 / 11.33$ & $-33.49 / 16.00$ & $43.78 / 71.34$ & $0.48 / 0.28$ & $0.60 / 0.55$ \\
\hline
\end{tabular}




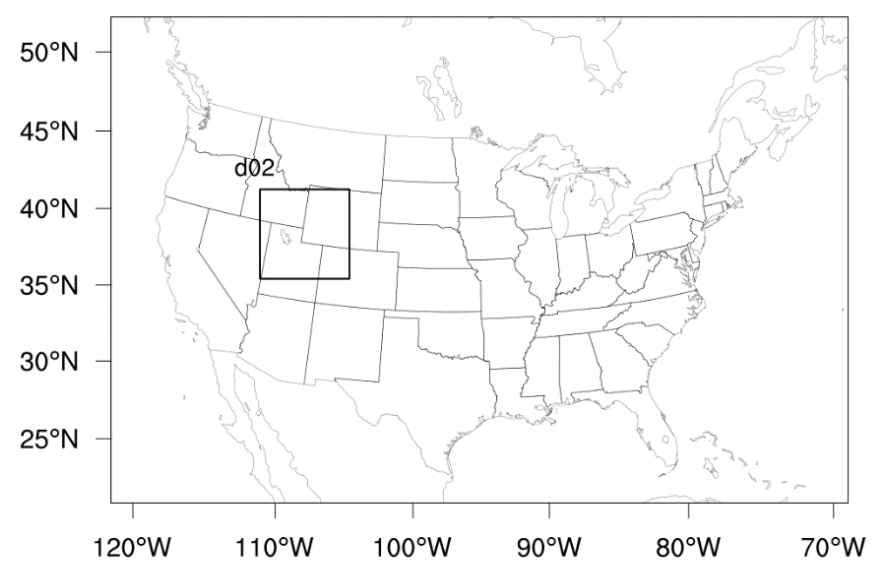

Figure S1 CMAQ domain setup

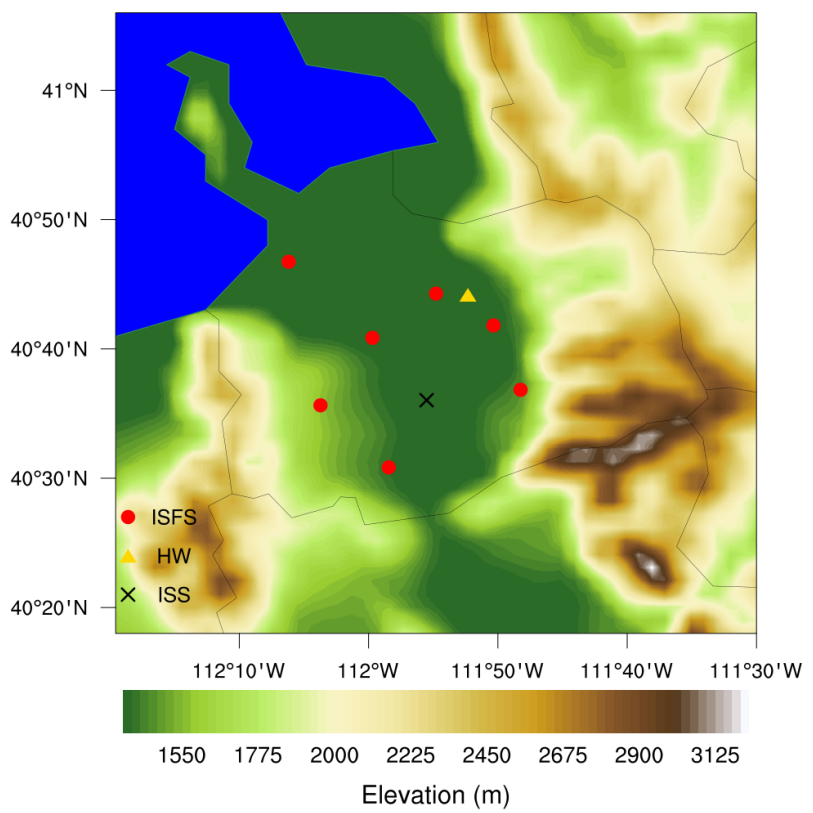

Figure S2 Topography map of the Salt Lake Valley (SLV) in Utah showing the observation sites. Red solid circles denote the seven ISFS sites that measured surface meteorology parameters and energy fluxes during the PCAPS field campaign. Yellow triangle indicates the location of the main air quality monitoring station (Hawthorne, HW) in Salt Lake City, Utah that is part of both EPA's Air Quality System (AQS) and Chemical Speciation Network (CSN). The NCAR ISS site is denoted by a black cross mark. 

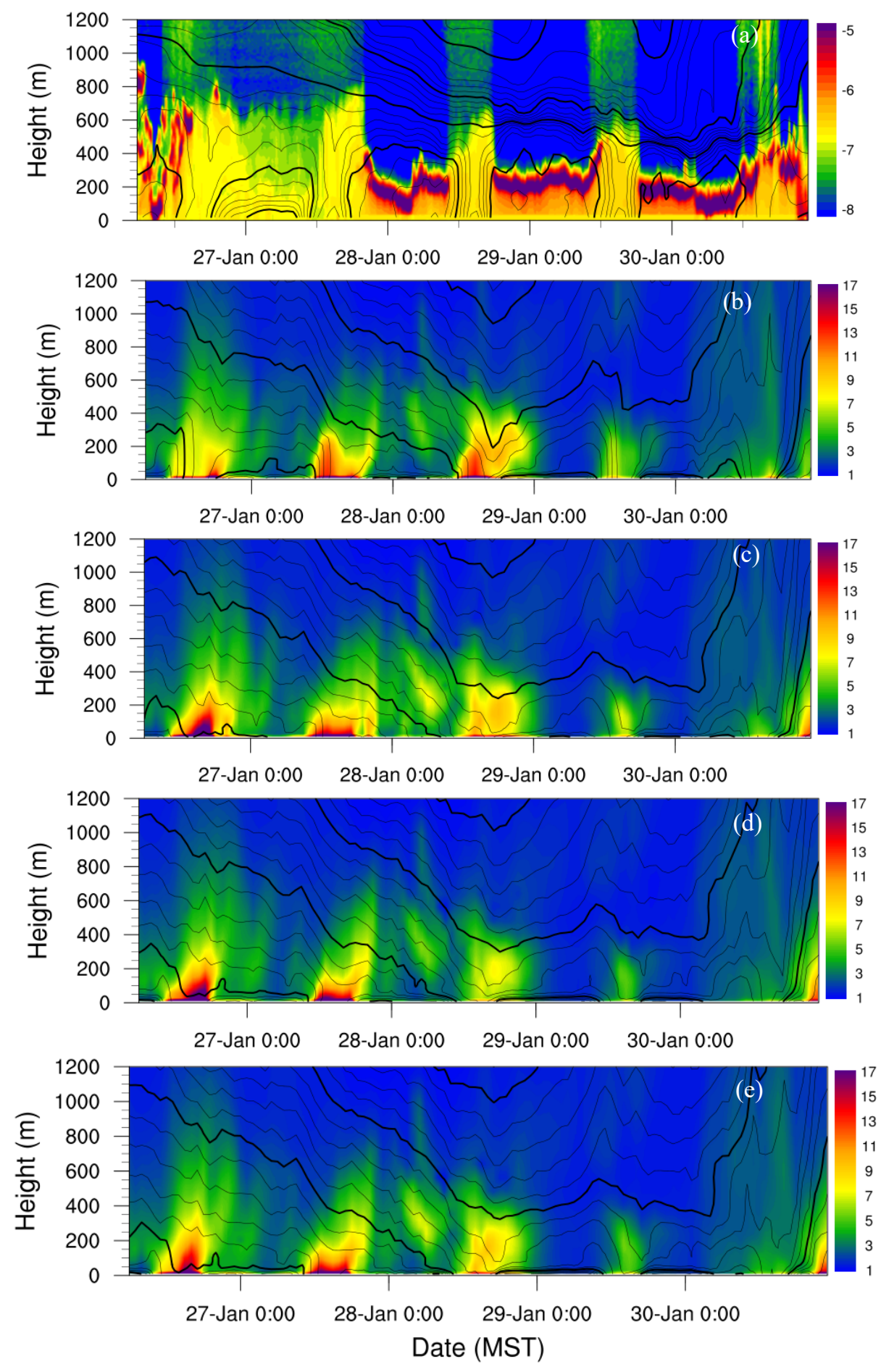

Figure S3 Time-height plot of hourly aerosol (color contour) and potential temperature (bold line every $5 \mathrm{~K}$ and thin line every $1 \mathrm{~K}$ ) for PCAP3. (a) Laser ceilometer backscatter $\left(\mathrm{m}^{-1} \mathrm{sr}^{-1}\right)$ and RASS potential temperature $(\mathrm{K})$, and simulated $\mathrm{PM}_{2.5}\left(\mu \mathrm{g} \mathrm{m}^{-3}\right)$ and potential temperature $(\mathrm{K})$ from (b) ModACM2, (c) ModYSU, (d) ModMYJ, and (e) ModMYNN. 


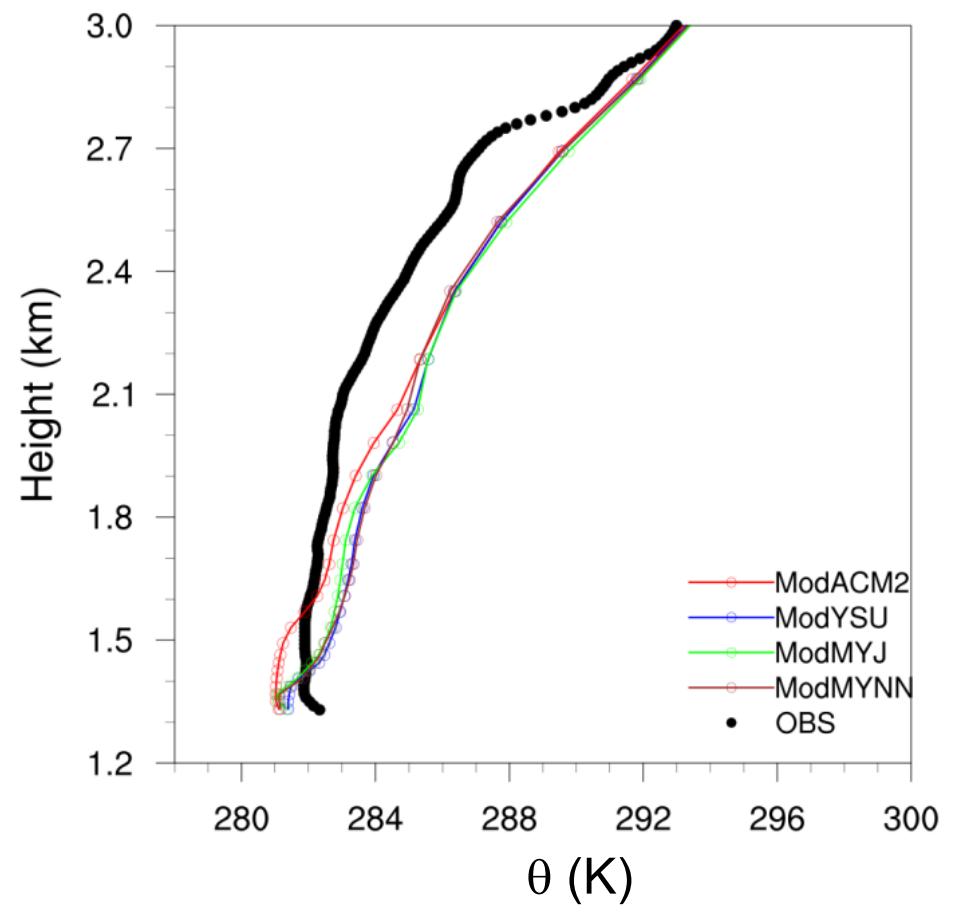

Figure S4 Simulated vertical profiles of potential temperature at 1200 MST 20 Jan 2010 at the NCAR ISS site located at the center of Salt Lake Valley. 

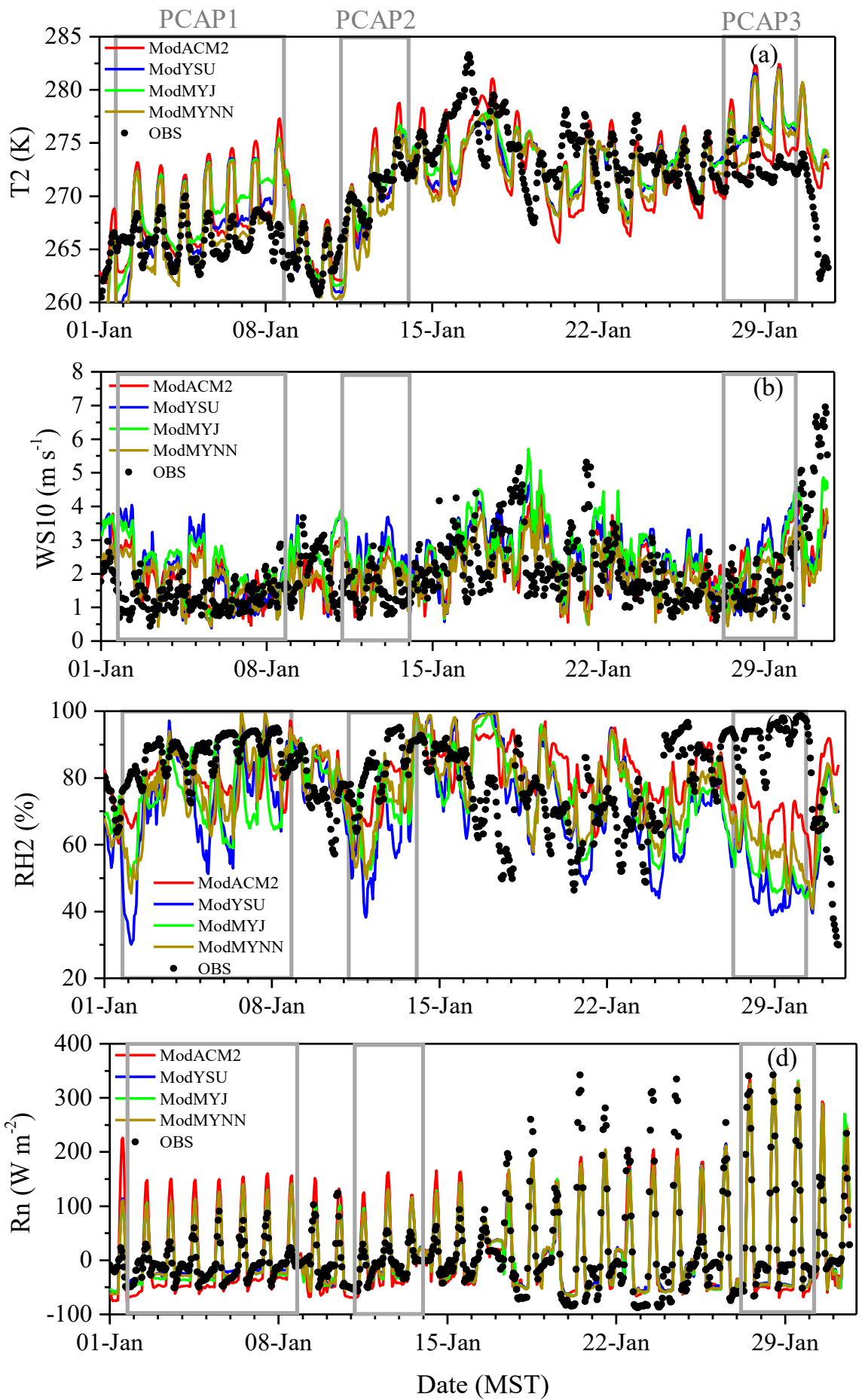

Figure S5 Time series of the hourly simulated and observed (a) 2-m temperature (T2), (b) 10-m wind speed (WS10), (c) 2-m relative humidity (RH2), and (d) net radiation (Rn) averaged over the seven ISFS sites. 


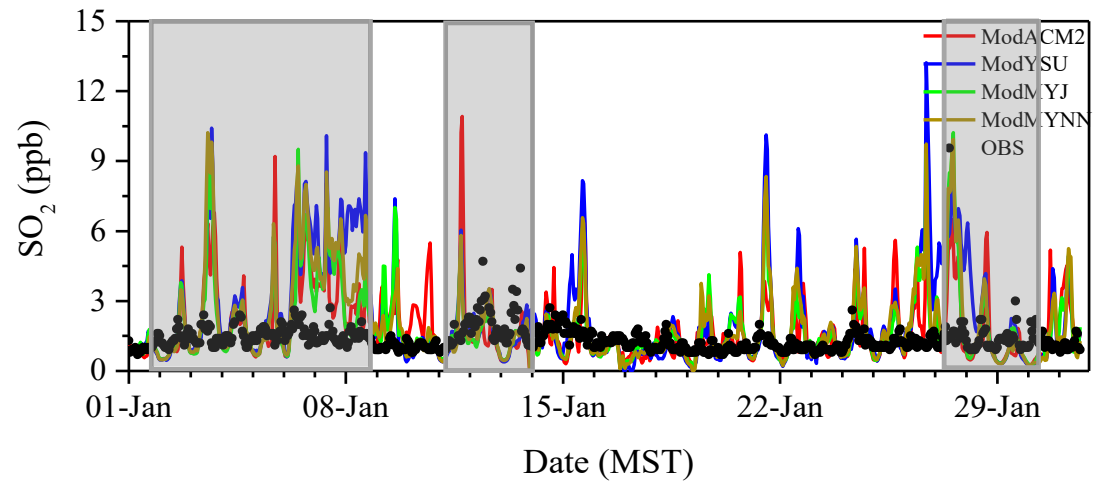

Figure S6 Time series of hourly simulated and observed mixing ratios of $\mathrm{SO}_{2}$
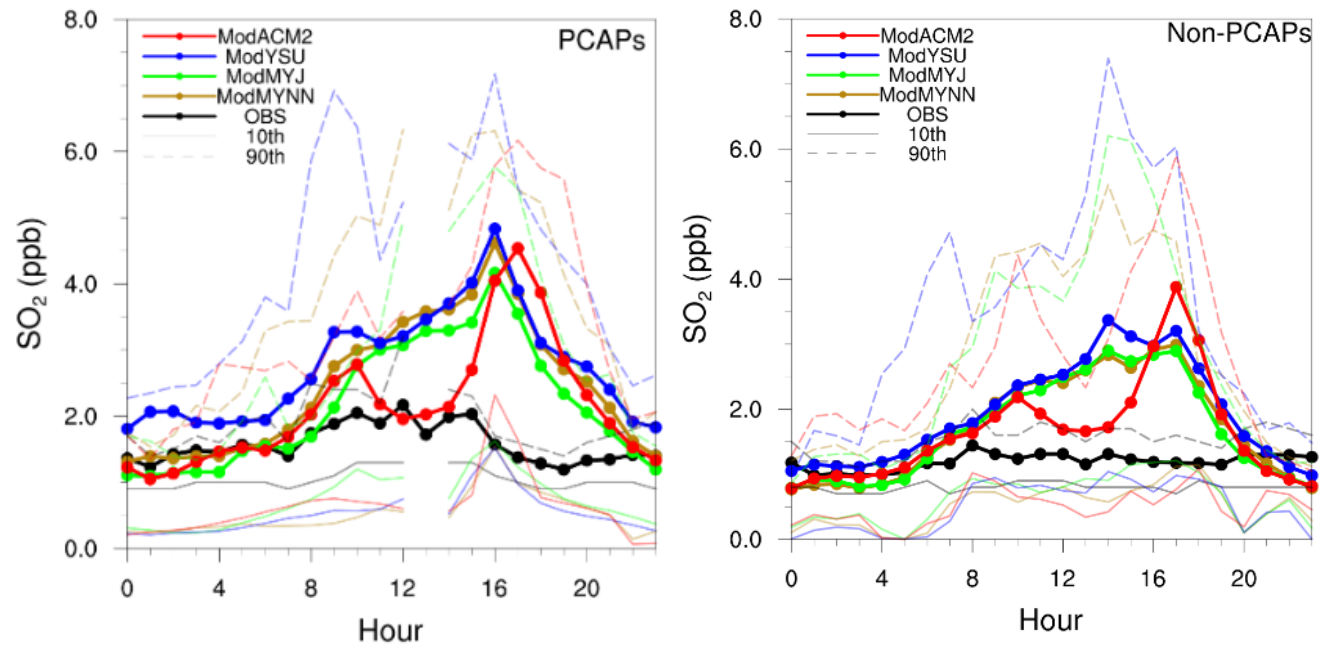

Figure S7 Diel variations of observed and modeled hourly mean values of $\mathrm{SO}_{2}$ during PCAP events and non-PCAP events. The lower $\left(10^{\text {th }}\right)$ and upper $\left(90^{\text {th }}\right)$ dectile values are presented for reference by opaque dashed lines and opaque solid lines, respectively. The data gaps in the PCAPs panel are because there are not enough data to plot the lower and upper dectile at that time. 


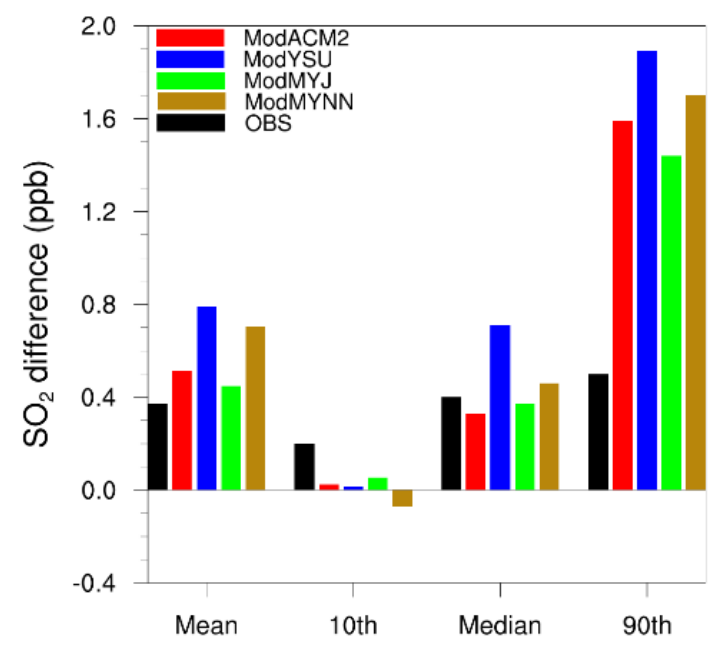

Figure S8 Bar chart of the observed and modeled difference in mean, $10^{\text {th }}$ percentile, median, and $90^{\text {th }}$ percentile of $\mathrm{SO}_{2}$ between hourly values during PCAPs and non-PCAPs events (PCAPsnon-PCAPs).

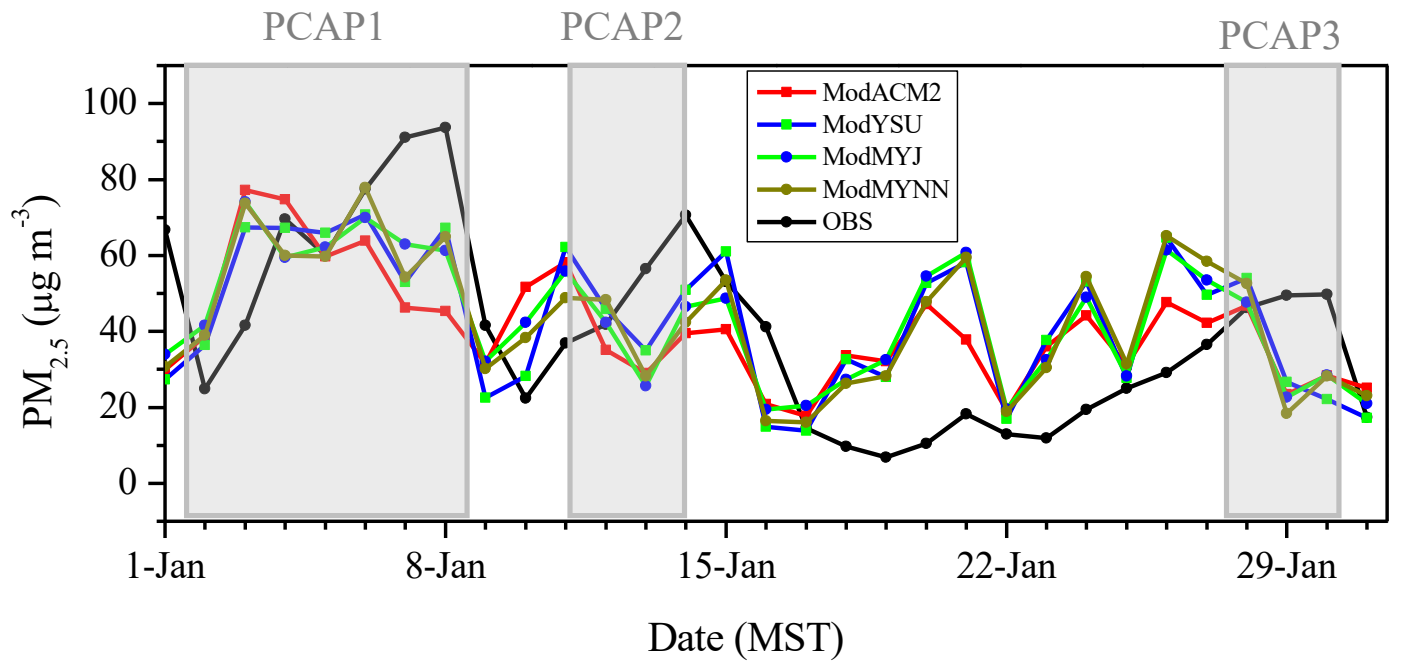

Figure S9 Daily maximum $\mathrm{PM}_{2.5}$ concentrations from observations and the four simulations. 


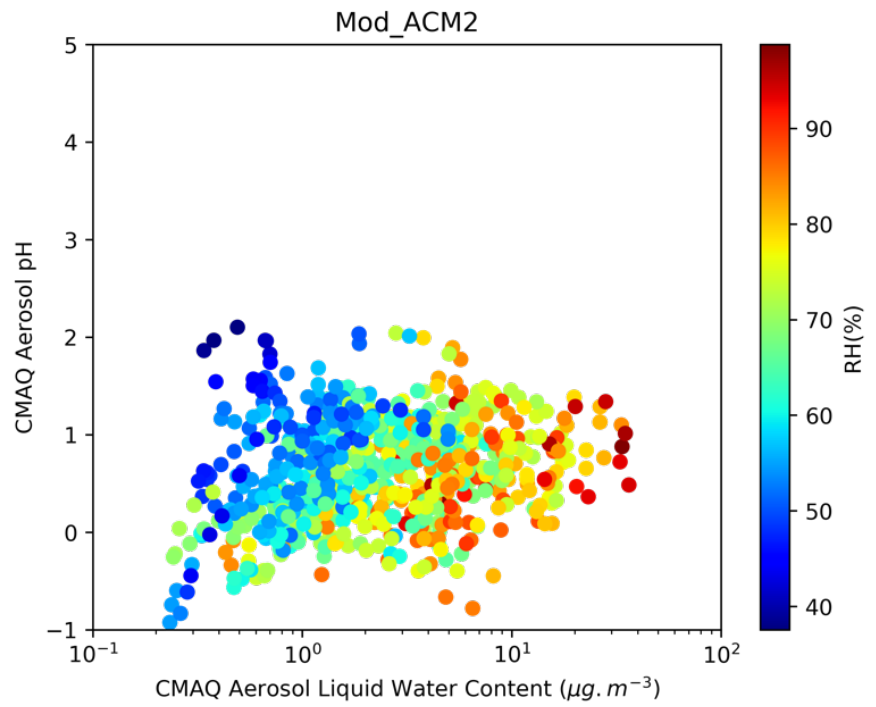

Figure S10 CMAQ simulated aerosol $\mathrm{pH}$ variations with simulated aerosol liquid water content from Mod_ACM2. The datapoints are color-coded by RH.
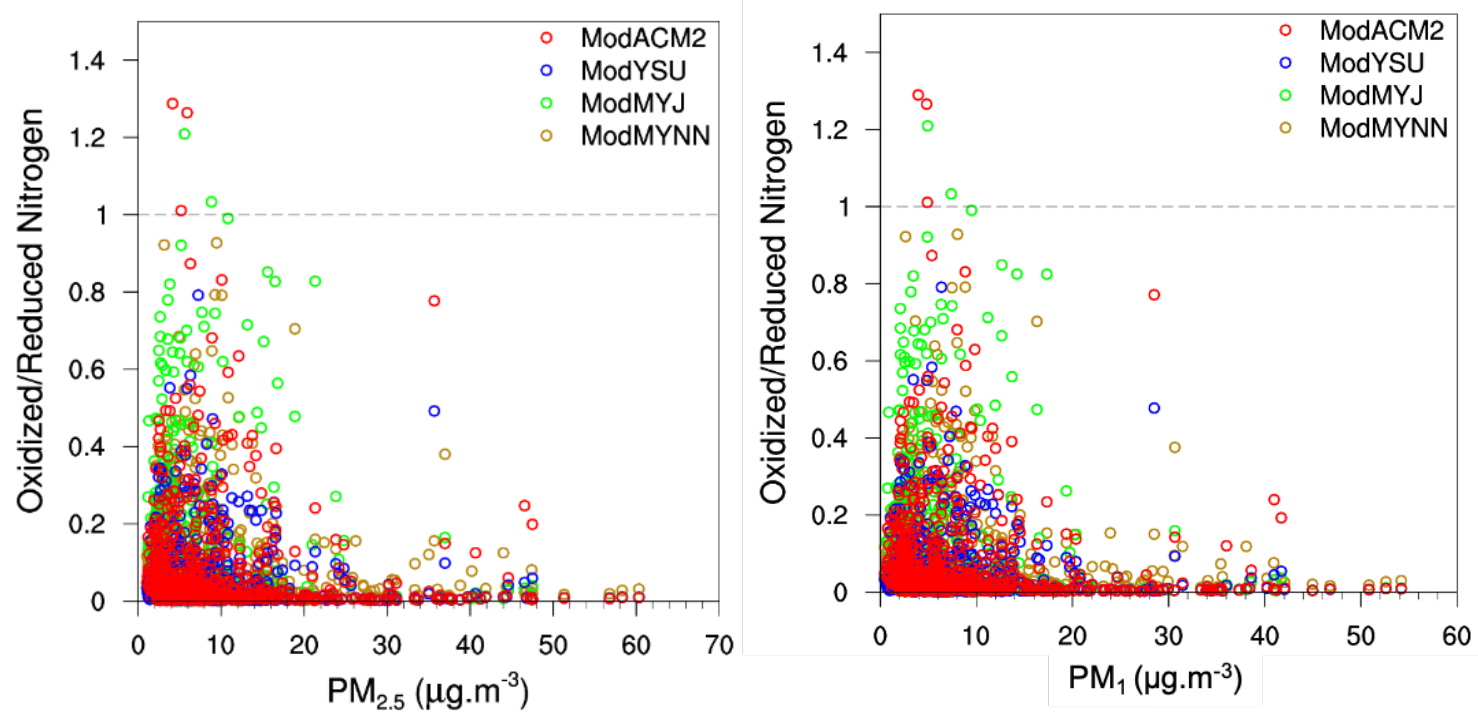

Figure S11 Simulated variations of the nitrogen ratio with $\mathrm{PM}_{2.5}$ and $\mathrm{PM}_{1}$ 


\section{References}

1. Baker, K.R., C. Misenis, M.D. Obland, R.A. Ferrare, A.J. Scarino, and J.T. Kelly, Evaluation of surface and upper air fine scale WRF meteorological modeling of the May and June 2010 CalNex period in California. Atmospheric Environment, 2013. 80: p. 299309.

2. Olson, J.B., J.S. Kenyon, W. Angevine, J.M. Brown, M. Pagowski, and K. Sušelj, $A$ description of the MYNN-EDMF scheme and the coupling to other components in WRFARW. 2019.

3. Cohen, A.E., S.M. Cavallo, M.C. Coniglio, and H.E. Brooks, A Review of Planetary Boundary Layer Parameterization Schemes and Their Sensitivity in Simulating Southeastern U.S. Cold Season Severe Weather Environments. Weather and Forecasting, 2015. 30(3): p. 591-612.

4. Thompson, G., P.R. Field, R.M. Rasmussen, and W.D. Hall, Explicit forecasts of winter precipitation using an improved bulk microphysics scheme. Part II: Implementation of a new snow parameterization. Monthly Weather Review, 2008. 136(12): p. 5095-5115.

5. Iacono, M.J., J.S. Delamere, E.J. Mlawer, M.W. Shephard, S.A. Clough, and W.D. Collins, Radiative forcing by long-lived greenhouse gases: Calculations with the AER radiative transfer models. Journal of Geophysical Research: Atmospheres, 2008. 113(D13).

6. Dudhia, J., Numerical study of convection observed during the winter monsoon experiment using a mesoscale two-dimensional model. Journal of the atmospheric sciences, 1989. 46(20): p. 3077-3107.

7. Kain, J.S., The Kain-Fritsch convective parameterization: an update. Journal of applied meteorology, 2004. 43(1): p. 170-181.

8. Otte, T.L., The Impact of Nudging in the Meteorological Model for Retrospective Air Quality Simulations. Part I: Evaluation against National Observation Networks. Journal of Applied Meteorology and Climatology, 2008. 47(7): p. 1853-1867.

9. Gilliam, R.C. and J.E. Pleim, Performance assessment of new land surface and planetary boundary layer physics in the WRF-ARW. Journal of Applied Meteorology and Climatology, 2010. 49(4): p. 760-774.

10. Curci, G., L. Ferrero, P. Tuccella, F. Barnaba, F. Angelini, E. Bolzacchini, C. Carbone, H.A.C. Denier van der Gon, M.C. Facchini, G.P. Gobbi, J.P.P. Kuenen, T.C. Landi, C. Perrino, M.G. Perrone, G. Sangiorgi, and P. Stocchi, How much is particulate matter near the ground influenced by upper-level processes within and above the PBL? A summertime case study in Milan (Italy) evidences the distinctive role of nitrate. Atmos. Chem. Phys., 2015. 15(5): p. 2629-2649.

11. Ivey, C.E., S. Balachandran, S. Colgan, Y. Hu, and H.A. Holmes, Investigating fine particulate matter sources in Salt Lake City during persistent cold air pool events. Atmospheric Environment, 2019. 213: p. 568-578.

12. Tesche, T.W., R. Morris, G. Tonnesen, D. McNally, J. Boylan, and P. Brewer, CMAQ/CAMx annual 2002 performance evaluation over the eastern US. Atmospheric Environment, 2006. 40(26): p. 4906-4919.

13. Pleim, J.E., A combined local and nonlocal closure model for the atmospheric boundary layer. Part I: Model description and testing. Journal of Applied Meteorology and Climatology, 2007. 46(9): p. 1383-1395. 
14. Pleim, J.E., A Simple, Efficient Solution of Flux-Profile Relationships in the Atmospheric Surface Layer. Journal of Applied Meteorology and Climatology, 2006. 45(2): p. 341-347.

15. Pleim, J.E. and A. Xiu, Development and Testing of a Surface Flux and Planetary Boundary Layer Model for Application in Mesoscale Models. Journal of Applied Meteorology, 1995. 34(1): p. 16-32.

16. Hong, S.-Y., Y. Noh, and J. Dudhia, A New Vertical Diffusion Package with an Explicit Treatment of Entrainment Processes. Monthly Weather Review, 2006. 134(9): p. 23182341.

17. Jiménez, P.A., J. Dudhia, J.F. González-Rouco, J. Navarro, J.P. Montávez, and E. GarcíaBustamante, A Revised Scheme for the WRF Surface Layer Formulation. Monthly Weather Review, 2012. 140(3): p. 898-918.

18. Ek, M.B., K.E. Mitchell, Y. Lin, E. Rogers, P. Grunmann, V. Koren, G. Gayno, and J.D. Tarpley, Implementation of Noah land surface model advances in the National Centers for Environmental Prediction operational mesoscale Eta model. Journal of Geophysical Research: Atmospheres, 2003. 108(D22).

19. Janić, Z.I., Nonsingular implementation of the Mellor-Yamada level 2.5 scheme in the NCEP Meso model. 2001: US Department of Commerce, National Oceanic and Atmospheric Administration, National Weather Service, National Centers for Environmental Prediction.

20. Nakanishi, M. and H. Niino, An Improved Mellor-Yamada Level-3 Model with Condensation Physics: Its Design and Verification. Boundary-Layer Meteorology, 2004. 112(1): p. 1-31.

21. Nakanish, M., Improvement of the Mellor-Yamada turbulence closure model based on large-eddy simulation data. Boundary-layer meteorology, 2001. 99(3): p. 349-378. 